Utah State University

DigitalCommons@USU

\title{
A Dynamic Analysis of the Global Timber Market Under Global Warming: An Integrated Modeling Approach
}

Dug Man Lee

Kenneth S. Lyon

Utah State University

Follow this and additional works at: https://digitalcommons.usu.edu/eri

\section{Recommended Citation}

Lee, Dug Man and Lyon, Kenneth S., "A Dynamic Analysis of the Global Timber Market Under Global Warming: An Integrated Modeling Approach" (2001). Economic Research Institute Study Papers. Paper 224.

https://digitalcommons.usu.edu/eri/224

This Article is brought to you for free and open access by the Economics and Finance at DigitalCommons@USU. It has been accepted for inclusion in Economic Research Institute Study Papers by an authorized administrator of DigitalCommons@USU. For more information, please contact digitalcommons@usu.edu.

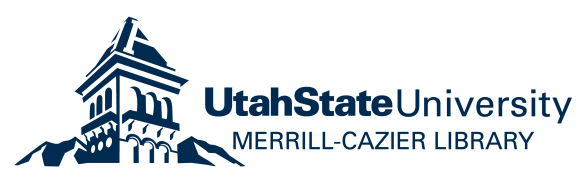


Economic Research Institute Study Paper

ERI \#2001-11

\section{A DYNAMIC ANALYSIS OF THE GLOBAL TIMBER MARKET \\ UNDER GLOBAL WARMING: AN INTEGRATED \\ MODELING APPROACH}

by

DUG MAN LEE

Department of Economics

Pusan National University

Pusan, Korea

KENNETH S. LYON

Department of Economics

Utah State University

3530 Old Main Hill

Logan, UT 84322-3530

April 2001 


\title{
A DYNAMIC ANALYSIS OF THE GLOBAL TIMBER MARKET \\ UNDER GLOBAL WARMING: AN INTEGRATED \\ MODELING APPROACH
}

\author{
Dug Man Lee, Lecturer \\ Department of Economics \\ Pusan National University \\ Pusan, Korea \\ Kenneth S. Lyon, Professor \\ Department of Economics \\ Utah State University \\ 3530 Old Main Hill \\ Logan, UT 84322-3530
}

The analyses and views reported in this paper are those of the author(s). They are not necessarily endorsed by the Department of Economics or by Utah State University.

Utah State University is committed to the policy that all persons shall have equal access to its programs and employment without regard to race, color, creed, religion, national origin, sex, age, marital status, disability, public assistance status, veteran status, or sexual orientation.

Information on other titles in this series may be obtained from: Department of Economics, Utah State University, 3530 Old Main Hill, Logan, Utah 84322-3530.

Copyright (C) 2001 by Dug Man Lee and Kenneth S. Lyon. All rights reserved. Readers may make verbatim copies of this document for noncommercial purposes by any means, provided that this copyright notice appears on all such copies. 


\title{
A DYNAMIC ANALYSIS OF THE GLOBAL TIMBER MARKET \\ UNDER GLOBAL WARMING: AN INTEGRATED \\ MODELING APPROACH \\ Dug Man Lee and Kenneth S. Lyon
}

\begin{abstract}
We developed a dynamic integrated modeling approach to identify the effect of global warming on the global timber market. The Timber Supply Model 2000, BIOME 3, and Hamburg were used as a suitable economic and ecological model. The TSM 2000 was adopted to model dynamic economic behavior in the global timber market. BIOME 3 was utilized as our steady state ecological model, and Hamburg as our general circulation model. The TSM 200 was developed to consider more important up-to-date components in the global timber market. We estimated dynamic ecological change based on the simulation results of BIOME 3 using Hamburg and the linearality assumptions about change in climate and ecosystem. With the estimates of dynamic ecological change, we modified the TSM 2000 to reflect the dynamic ecological change caused by climate change. After simulating the nonclimate base scenario and the climate change scenario of the TSM 2000, we identified that global warming has a positive effect on the global timber market through an increase of timber productions causing stumpage prices to be lower than they otherwise would have been. In the welfare sense, we also examined that global warming is economically beneficial to society through the global timber market. For sensitivity analyses, we performed these simulation procedures under three different timber demand growth scenarios.

JEL Classification: Q23

Key words: optimal control theory, global warming, global timber market, timber supply model, ecological change
\end{abstract}




\section{A DYNAMIC ANALYSIS OF THE GLOBAL TIMBER MARKET \\ UNDER GLOBAL WARMING: AN INTEGRATED \\ MODELING APPROACH}

\section{INTRODUCTION}

Scientists and policy makers alike are concerned about global warming caused by the accumulation of carbon dioxide in the atmosphere. A significant number of studies have built comprehensive assessment models of carbon dioxide concentrations in the atmosphere over long time periods; however, most of these are deficient in the sense that they do not develop integrated assessment models that capture economic effects associated with global warming. In this vein, our research, as shown below, contributes to a growing body of literature that attempts to develop dynamic integrated models of ecosystem and economic system interactions that arise from predictions of global warming. We focus on the global timber market as a particular inquiry of global warming.

As global warming forces ecosystems to migrate toward the poles, the distribution of ecosystem types and the productivity of ecosystems will be altered. The transformation and adjustment of ecosystems resulting from climate change also change the environmental conditions under which natural resources, including forest products, are extracted and regenerated. It has been discussed and predicted that changes of forest types occur along two dynamic paths: dieback and regeneration (Shugart 1984, Solomon 1986, King and Neilson 1992). As climate change cause forest types to change along these dynamic paths, the global timber market will adjust as timber availability is altered.

In this context, we have developed an integrated modeling approach that identifies the effect of global warming on the global timber market. Most literatures that studied this objective have only investigated the effect of global warming on timber market in limited regions. Binkley (1988) studied the impact of global warming on boreal forests. Joyce et al. (1995), Burton et al. (1998), and Sohngen and Mendelsohn (1998) focused 
only on the conterminous U.S. Perez-Garcia et al. (1997) and Sohngen et al. (1997) extended the effect of global warming on the global timber market. Except for Sohngen and Mendelsohn (1998), and Sohngen et al. (1997), these studies used comparative static analysis, and compared steady state equilibria. They considered neither dynamic ecological change nor dynamic economic behavior of the timber market.

For our integrated modeling approach, we used the Timber Supply Model developed by Sedjo and Lyon (1990), and extended it to include additional components. BIOME 3 (Haxeltine and Prentice, 1996) was adopted as our steady state ecological model, and Hamburg (Claussen, 1996) as our general circulation model to investigate the change of climate variables when carbon dioxide is doubled in the atmosphere. Because there are no dynamic ecological models that span the globe, we imposed linearity assumptions about ecosystem adjustment to climate change. We do this to derive a predicted time path of relevant ecological changes such as forest dieback hectares and regeneration hectares, and to predict the dynamic productivity change.

We modified the extended TSM (which is referred to as TSM 2000) to reflect these dynamic ecological changes. Then, we simulated a non-climate change base scenario and the climate change scenario using TSM 2000 to predict the effect of global warming on the global timber market. We performed these procedures for three different timber demand scenarios to observe the sensitivity of the level of timber demand. These include normal timber demand (ND) growth, high timber demand (HD) growth, and very high timber demand (VHD) growth.

Below we first specify and formulate TSM 2000. Second, we develop our procedures for estimating the relevant dynamic ecological changes caused by global 
warming. These include dynamic forest land area changes and productivity changes.

Third, the simulation results are reported and discussed for each scenario. This includes a discussion of the sensitivity results and welfare implications.

\section{DYNAMIC TIMBER SUPPLY MODEL}

Alternative dynamic economic models of timber market behavior include [Berck (1979), Brazee and Mendelsohn (1990), Adams et al. (1996), Sohngen and Mendelsohn (1998), Sohngen et al. (1999)], and the TSM [Sedjo and Lyon (1990, 1996)]. The TSM has the characteristics that we desire; hence, adapted it. In general, the volume harvested in the TSM is affected by seven types of adjustments. These are 1) rotation length of age, 2) the rate of drawn-down of old growth inventories, 3) the number of forested land classes that are utilized in the harvest, 4) the level of regeneration input applied to the various land classes, 5) the rate at which new industrial plantation are added to the world's timber producing regions, 7) changed in production from non-responsive region of the world (Lyon and Sedjo, 1992) ${ }^{1}$. The TSM provides economically efficient solutions in the sense that it maximizes total benefit to the society as a whole, not the net income stream of individual landowner.

\section{Description of TSM 2000}

To develop TSM 2000 we modified TSM in the following ways. First, the TSM 2000 considers the former Soviet Union to be a part of the responsive region. We postulate that the former Soviet Union will participate in the global timber market, and that it will play a critical role in supplying stumpage to the global timber market since it is estimated that it contains approximately 25 percent of worldwide forest growing stock

\footnotetext{
${ }^{1}$ In the TSM, responsive regions includes U.S South, U.S Pacific Northwest, Eastern Canada, Western Canada, Nordic Europe, Asia-Pacific, and the emerging region.
} 
(Backman and Waggener, 1991). For this research, we subdivided the former Soviet Union into three sub-regions: European USSR, West Siberia, and East Siberia. Also, according to ecosystem types and the degree of accessibility for harvesting, these three sub-regions consist of sixteen land classes: eight land classes for European USSR, four land classes for West Siberia and East Siberia, respectively. These are identified more concretely below.

Second, we included more plantation forests in the emerging region in the TSM $2000^{2}$. Plantation forest in India, Asia-Pacific region, and sub-regions in Africa except South Africa are not included in the TSM as the emerging region. According to Sedjo (1995), both tropical and subtropical regions have experienced an increase in plantation forest. Land areas in these regions, which are exploited for agricultural production or were being conserved for the future use, are now being turned into plantation forest. About six million hectares had been planted in the emerging region by 1980 (Sedjo and Lyon, 1990), however, it is estimated that plantation forest acreage included in these area were about thirty eight million hectares in 1990 (UNFAO, 1993a, 1993b, 1995).

Third, there has been a trend to withdraw forestland from timber harvesting and conserve it for wilderness, ecological reserves, parks, scenic corridors, and other purposes in many major timber producing countries. Recent publications $(1990,1994)$ of the International Union Conservation of Nature and Natural Resources (IUCN) included all the areas designated to be protected by individual governments as well as the international organizations. Yan (1996) calculated the conserved hectares of forest for seven responsive regions being included in the TSM since 1981 (1980 for Asia Pacific 
region) based on publication of IUCN (1994). He designed nine scenarios of the forest conservation by combining these calculations with more information on conservation actions for each responsive region. Current trends to promote conservation of forest for environmental protection suggest that conservation patterns modeled in TSM 2000 will be an important factor affecting worldwide timber supply. In this respect, we modeled conservation of forest for each land class in each region by adopting Yan's (1996) scenario five. Below we discus the forest conservation ratios that we use for the subregions of the former Soviet Union ${ }^{3}$.

Fourth, the TSM $(1990,1996)$ considered only twenty-two land classes in seven responsive regions to project the optimal time profile of important endogenous variables in the model. To meet our research objective, we considered the change of distribution of ecosystem type (vegetation pattern) and change of productivity of ecosystem type after climate change. When we examined the change of distribution of ecosystem types on the basis of BIOME 3 predictions using Hamburg as our GCM, we observed that in some regions a large potion of an ecosystem type would be transformed into other ecosystem types after climate change. This reflects the fact that some species die out from the area where they are currently standing, and new species are regenerated naturally or planted by human beings for economic benefit. In this respect, we subdivided land classes in more detail in the TSM 2000 in order to include the ecological detail acquired from the BIOME 3 predictions on ecosystem system change. Consequently, TSM 2000 includes forty-two land classes in ten responsive regions.

\footnotetext{
${ }^{2}$ Emerging region in the TSM includes Brazil, Chile, Venezuela, New Zealand, Australia, South Africa, Spain, Portugal.
} 
Formulation of TSM 2000

We now describe the model. Net surplus in the year $j$ is defined as

$$
s_{j}=\int_{0}^{Q_{j}} D_{j}^{s}(n) d n+\int_{0}^{\widetilde{Q}_{j}} D_{j}^{p}(n) d n-C_{j}
$$

where $Q_{j}$ is the quantity or volume of timber for solidwood harvested in year $j ; D_{j}^{s}\left(Q_{j}\right)$

is the inverse demand function of industrial solidwood in year $j ; \widetilde{Q}_{j}$ is the volume of timber for pulpwood harvested in year $j ; D_{j}^{p}\left(\widetilde{Q}_{j}\right)$ is the demand function of industrial pulpwood in inverse form; and $C_{j}$ is the total cost in year $j$. The total costs are the summation of harvest, access, transportation costs $\left(\mathrm{CH}_{j}\right)$ and regeneration cost $\left(\mathrm{CR}_{j}\right)$. Harvesting and transportation costs in year $j$ depend on the total volumes harvested by land class, and regeneration costs depend on hectares harvested (regenerated) and the level of input used.

For the formulation, let us define $x_{h j}$ be a vector of hectares of trees in each age group for land class $h$ in year $j$ with elements $x_{h i j}$. The subscript $h, i$, and $j$ are corresponding for land class, age group, and the year, respectively. $x_{h i j}$ denotes for land class $h$, the number of hectares of age group $i$ in year $j$; let $z_{h j}$ be the vector of state variables for the regeneration input with elements $z_{h i j}$, the level of regeneration input associated with age group $i$ in year $j$ for land class $h$. Next, $u_{h j}$ is defined to be control vector of hectares harvested. The elements of $u_{h j}$ denote for land class $h$ the portion of

\footnotetext{
${ }^{3}$ For more details about Yan's scenario five, see chapter four of Yan's dissertation (1996). And for the former Soviet Union, the conservation ratio of forest for European USSR, West Siberia, and East Siberia are $29 \%$, and $16 \%$, and $14 \%$, respectively.
} 
the hectares of trees in age group $i$ harvested in year $j$. Let $w_{h j}$ be the level of regeneration input per hectare for those hectares regenerated in year $j$, and $p_{w h}$ be the price of regeneration input for land class $h$.

The merchantable volume of timber per hectare for land class $h$ in time period $j$ for a stand regenerated $i$ time periods ago depends on $i$ and on the magnitude of the regeneration input used on this stand $\left(z_{h i j}\right)$. We denote this merchantable volume as follows;

$$
q_{h i j}=f_{h}\left(i, z_{h i j}\right)
$$

This volume is divided between solidwood and pulpwood using variable proportions which vary by land class, with $\phi_{h}$ the portion going to solidwood and $\left(1-\phi_{h}\right)$ the portion going to pulpwood. The proportion $\phi_{h}$ is a constant elasticity function of the price of solidwood relative to the price of pulpwood $\left(p_{j}^{s} / p_{j}^{p}\right)$. When this relative price is greater than or equal to 1.05 , it is given by

$$
\phi_{h j}=A_{h}\left(p_{j}^{s} / p_{j}^{p}\right)^{\varepsilon}
$$

where $p^{s}$ and $p^{p}$ are solidwood and pulpwood price, respectively; $\varepsilon$ is the elasticity of $\phi$ with respect to relative price, which is the same for all land classes, and $A_{h}$ is a scaling factor that varies by land class. When, however, the relative price is between 1 and 1.05 we use the function

$$
\phi_{h j}=\left[\left(p_{j}^{s} / p_{j}^{p}\right)-1\right]^{\varepsilon 2 h}
$$

where $\varepsilon 2 h$ is selected so that these two functions for $\phi_{h j}$ give the same value at a relative price of 1.05 . Note that the value of this function approaches zero as relative price 
approaches one. For the base case and several scenarios to be considered, we use an elasticity, $\varepsilon$, of 0.6 , and select the scaling factors so that the reference percents solidwood given in Table 1 would exist at a relative price of 1.5 .

With these definitions, the volume of commercial timber harvested for solidwood and pulpwood from land class $h$ in year $j, Q_{h j}$ and $\widetilde{Q}_{h j}$ is given by

and

$$
\begin{aligned}
& Q_{h j}=\phi_{h j} u_{h j}^{\prime} X_{h j} q_{h j} \\
& \widetilde{Q}_{h j}=\left(1-\phi_{h j}\right) u_{h j}^{\prime} X_{h j} q_{h j} \\
& Q_{j}=\sum_{h} Q_{h j}, \quad \widetilde{Q}_{h j}=\sum_{h} \widetilde{Q}_{h j}
\end{aligned}
$$

where $X_{h j}$ is a diagonal matrix using the elements of $x_{h j}$, and the total volume harvested in the responsive regions is the summation of these over all land classes.

Costs including harvest, access, and transportation cost for land class $h$ is a function of the volume harvested in that land class;

$$
C H_{h j}=c_{h}\left(Q_{h j}+\widetilde{Q}_{h j}\right)
$$

and regeneration cost for land class $h$ in time period $j$ is given by

$$
C R_{h j}=\left(u_{h j}{ }^{\prime} x_{h j}+v_{h j}\right) p_{w h} w_{h j}
$$

where the inner product in parenthesis gives the hectares harvested in land class $h, v_{h j}$ is the exogenously determined number of hectares of new forest land in land class $h$, and the product of the last two terms gives expenditure per hectare. This yields the costs as

$$
C_{j}=\sum_{h}\left(C H_{h j}+C R_{h j}\right)
$$

With these definitions, the objective function of TSM 2000 will be the discounted present value of the net surplus as follows; 


$$
S_{0}\left(x_{0}, z_{0}, u, w\right)=\sum_{k=0}^{J-1} \rho^{k} S_{k}+\rho^{J} S_{J}^{*}\left(x_{J}, z_{J}\right)
$$

where $\rho$ is the discount factor, $e^{-r}$, with $r$ the market interest rate; $J$ is the last time period of the modeled time horizon; $u$ is any admissible set of control vectors, $u_{0}, u_{1}, \ldots, u_{J-1}$ (including all land classes); $w$ is any set of admissible control scalars, $w_{0}, w_{1}, \ldots w_{J-1}$ (also covering all land classes); and $S_{J}{ }^{*}(\cdot$,$) is the optimal terminal value$ function.

Equation (6) is to be maximized subject to the laws of motions of state variables and constraints on the value of control variables. The portions of hectares harvested are constrained to be non-negative and less than or equal to 1 , and the regeneration inputs are constrained to be non-negative;

$$
\begin{array}{ll}
0 \leq u_{h i j} \leq 1 & \text { for all } h, i, j \\
0 \leq w_{h j} & \text { for all } h, j
\end{array}
$$

The laws of motion for the given system are given by

$$
\begin{array}{ll}
x_{h, j+1}=\left(A+B U_{h j}\right) x_{h j}+v_{h j} e & \text { for all } h, j \\
z_{h, j+1}=A z_{h j}+w_{h j} e & \text { for all } h, j
\end{array}
$$

where 


$$
\begin{aligned}
& A=\left[\begin{array}{cccccccc}
0 & 0 & 0 & 0 & . & . & . & 0 \\
1 & 0 & 0 & 0 & . & . & . & 0 \\
0 & 1 & 0 & 0 & . & . & . & 0 \\
0 & 0 & 1 & 0 & . & . & . & 0 \\
0 & 0 & 0 & 1 & . & . & . & 0 \\
. & . & . & . & . & . & . & . \\
. & . & . & . & . & . & . & . \\
0 & 0 & 0 & 0 & 0 & 0 & 1 & 0
\end{array}\right] \quad e=\left[\begin{array}{l}
1 \\
0 \\
0 \\
0 \\
\cdot \\
\cdot \\
\cdot \\
0
\end{array}\right] \\
& B=\left[\begin{array}{cccccccc}
1 & 1 & 1 & 1 & . & . & . & 1 \\
-1 & 0 & 0 & 0 & . & . & . & 0 \\
0 & -1 & 0 & 0 & . & . & . & 0 \\
0 & 0 & -1 & 0 & . & . & . & 0 \\
0 & 0 & 0 & -1 & . & . & . & 0 \\
. & . & . & . & . & . & . & . \\
. & . & . & . & . & . & . & . \\
0 & 0 & 0 & 0 & 0 & 0 & -1 & 0
\end{array}\right]
\end{aligned}
$$

$A, B$, and $U$ are $M$-square matrices; $U_{h j}$ is a diagonal matrix using the elements of $u_{h j}$; and $e$ is an $M$-vector where $M$ is equal to or greater than the index number of the oldest age group in the problem.

\section{Solution Techniques}

The problem of maximizing objective function (6), subject to the constraint equations (7a) through (8b) is a discrete time, optimal control problem that can be solved by the discrete time maximum principle. We next apply the maximum principle for this timber supply problem and examine the necessary conditions. The maximum principle is a theorem that states that the constrained maximization of equation (6) can be decomposed into a series of subproblems. In each time period, the following Hamiltonian is maximized with respect to $u_{h j}$ and $w_{h j}$ subject to the constraints. 
The Hamiltonian for year $j$ is

$$
\begin{gathered}
H_{j}=\int_{0}^{Q_{j}} D_{j}^{s}(n) d n+\int_{0}^{\tilde{Q}_{j}} D_{j}^{p}(n) d n-C_{j}+\sum_{h} \lambda_{h, j+1}^{\prime}\left[\left(A+B U_{h j}\right) x_{h j}+v_{h j} e\right] \\
+\sum_{h} \psi_{h, j+1}^{\prime}\left(A z_{h j}+p_{w h} w_{h j} e\right)
\end{gathered}
$$

where

$$
\begin{array}{ll}
\lambda_{h j}=\rho\left[\partial S_{J}^{*}\left(x_{J}, z_{J}\right) / \partial x_{h j}\right] & (j=1, \ldots \ldots \ldots J) \\
\lambda_{h j}=\rho\left[\left(\partial s_{j}^{*} / \partial x_{h j}\right)+\left(A+B U_{h j}^{*}\right)^{\prime} \lambda_{h, j+1}\right] & (j=1, \ldots \ldots \ldots J-1)
\end{array}
$$

and

$$
\begin{aligned}
& \psi_{h j}=\rho\left[\partial S_{J}^{*}\left(x_{J}, z_{J}\right) / \partial z_{h j}\right] \\
& \psi_{h j}=\rho\left[\left(\partial s_{j}^{*} / \partial z_{h j}\right)+A^{\prime} \psi_{j+1}\right]
\end{aligned}
$$$$
(j=1, \ldots \ldots \ldots)
$$$$
(j=1,
$$

The derivatives with respect to vectors are gradient vectors, and $S_{j+1}^{*}()$ is the solution function in $j+1$. The solution function in year $j+1$ can be conceptualized as the result of an application of Bellman's optimality principle and backward recursion. The $\lambda_{h j}$ and $\psi_{h j}$ are costate (adjoint) vectors and identify the shadow values of the hectares of forest and the regeneration input, respectively, in each age group in year $j$. The necessary conditions for constrained maximization of the Hamiltonian in equation (9) are both necessary and sufficient for the constrained maximization of equation (6). The correspondence of necessary conditions is the essence of the maximization principle (Halkin, 1966). The conditions are sufficient because an equivalent form of the constrained maximization of (6) can be shown to be the maximization of a quasi-concave function subject to a set of linear constraints. 
The Lagrnagian function and the Kuhn-Tucker necessary conditions of this optimization problem are

$$
\begin{aligned}
& L_{j}^{H}=H_{j}+\sum_{h} \xi_{h j}{ }^{\prime}\left(1-u_{h j}\right) \\
& \partial L_{j}^{H} / \partial u_{h j}=\left[D\left(Q_{j}\right)-C_{h}{ }^{\prime}\left(Q_{h j}\right)\right] X_{h j} q_{h j}-x_{h j} p_{w h} w_{h j} \\
& \left.+X_{h j}^{\prime} B^{\prime} \lambda_{h, j+1}-\xi_{h j}^{\prime} \leq 0 \quad \text { (for all } h\right) \\
& \left(\partial L_{j}^{H} / \partial u_{h i j}\right) u_{h i j}=0 \quad \text { (for all } h \text { and } i \text { ) } \\
& \partial L_{j}^{H} / \partial w_{h j}=-u_{h j} x_{h j} p_{w h}+\psi_{h, j+1} p_{w h} \leq 0 \quad(\text { for all } h) \\
& \left.\left(\partial L_{j}^{H} / \partial w_{h j}\right) w_{h i j}=0 \quad \text { (for all } h \text { and } i\right) \\
& \left.\partial L_{j}^{H} / \partial \xi_{h j}=\left(1-u_{h j}\right) \geq 0 \quad \text { (for all } h\right) \\
& \left.\left(\partial L_{j}^{H} / \partial \xi_{h j}\right) \xi_{h i j}=0 \quad \text { (for all } h \text { and } i\right)
\end{aligned}
$$

These Kuhn-Tucker conditions, the laws of motion for the state variables (equations 8a and $8 \mathrm{~b}$ ), and the laws of motion for costate variables (equations 10a and 10b) identify a two-point boundary value problem that can be used to solve both theoretical and numerical problems. These are the equations that we solve to find the optimal time paths for the scenario analyses.

\section{ECOLOGICAL CHANGE IMPACTED BY GLOBAL WARMING}

Because a dynamic ecological model that covers the globe has not yet been developed, we use a steady state ecological model to predict the steady state ecological equilibrium before and after climate change, and then linearize the variables between the end points. We first use a general circulation model (GCM) to estimate the effects upon 
climate change a doubling of atmospheric carbon. Then, using these climate results as inputs, the steady state ecological model was simulated. The output of this was the change of the distribution of ecosystems by type, and the change in the productivity of ecosystems across the globe. In general, steady state ecological models are classified into two categories. Biogeographical distribution models (Neilson and Marks 1992, Prentice et al. 1992, and Woodward et al. 1995) predict the change in the distribution of ecosystem types and Biogeochemical cycle models (Mellio 1993, Parton et al. 1988, Parton et al. 1993, Running and Coughland 1988, and Running and Cower 1991) predict the change in the productivity of the ecosystems. In our research, we adopted BIOME 3 to observe steady state ecological change using Hamburg as our GCM. BIOME 3 includes both a Biogeographical distribution model and a Biogeochemical cycle model within a single global framework. The output of BIOME 3 consists of a quantitative vegetation state description in terms of the dominant plant function types, the total leaf index, and the net primary productivity ${ }^{4}$.

When carbon dioxide is doubled in the atmosphere, the steady state equilibrium for climate and ecosystems will respond dynamically. To compensate the limitations of steady state ecological models, we assumed that both climate change and ecosystem change occurs as a linear function of carbon dioxide accumulation in the atmosphere as Sohngen et al. (1997) did. This assumption follows the Intergovernmental Panel of Climate Change (IPCC) convention and the assumption Sohngen et al. (1997) imposed. The IPCC (1990) predicted a linear increase of temperature from 1990 to 2060, when the carbon dioxide concentration in the atmosphere is to be doubled. Also, Sohngen et al.

\footnotetext{
${ }^{4}$ For more detail about the plant functional types, see the Haxeltine and Prentice (1996). In BIOME 3, nine legends denotes the forests.
} 
(1997) assumed that climate variables are linearly increasing from 1990 to 2060, and after 2060, climate variables stabilize, with ecosystems doing the same. We have already steady state predictions for current situation and for 2060, and linearlize the change between these points. These include both climate and ecological variables. Within this model, this implies time paths for hectares of forest and the net primary productivity of these forests. This yields dynamic ecological changes that decomposed into dynamic land area change and dynamic productivity change of ecosystem types. The implementation of the linearlity assumptions is detailed below.

\section{Dynamic Land Area Change}

Biospheric scientists (Shugart 1984, Solomon 1986, King and Neilson 1992) suggested that there are two processes of dynamic ecosystem type change as climate changes over time. One is dieback and the other is regeneration. Dieback occurs when environmental conditions of the forest significantly deviate from those to which the current growing trees are accustomed. Changing climate conditions continuously harass growing trees and causes standing trees to stop growing. Eventually, standing trees die out. According to regeneration, as climate changes, current forests are growing continuously in the sites where they are currently standing. Regeneration occurs slowly through the gradual competitive displacement of forest types or plantation management with species better suited to changed climate conditions. As existing forests are harvested or die out naturally, however, old species are not regenerated. Instead, new species naturally migrate into the sites with a time lag or are planted by human beings for economic benefit. 
In this context, we first identified the change in potential forest. To do this we took the BIOME 3 simulation results and eliminated non-forest land areas. Non-forest areas include farmland and settlement, city complexes, paddy, cropland and pasture, costal, and water and islands ${ }^{5}$. Using these hectares of potential forest for before and after climate change, we calculated the dieback ratio, and the regeneration ratio for each ecosystem type. We did this for the land area in each of the responsive regions covering our 42 land classes. We considered two factors in choosing ecosystem types in each responsive region. These factors include dominant forest types for commercial use, as well as a degree of ecological transformation after climate change. Each land class in the TSM 2000 was classified according to its biological and geographical characteristics such as ecosystem type as well as the degree of harvesting accessibility. Thus, the regional steady state land area changes were disaggregated into each land class according to its ecosystem type. Under linearity assumptions that we imposed to estimate dynamic ecological change, we estimated dynamic land area change of all forty two land classes such as forest dieback hectares per year and regeneration hectares per year.

\section{Dynamic Productivity Change}

As part of dynamic ecological specification we assumed that net primary productivity (NPP) adjustment occurs proportionally to climate change over time period. The NPP is not a dynamic concept, but a steady state concept in the sense that the Biogeochemical cycle model predicts the equilibrium NPP at given time. Thus, the dynamic path of NPP was assumed to be linear over the period of climate change. In the context that the NPP is the net amount of carbon garnered for plant growth, changes in

\footnotetext{
${ }^{5}$ We chose non-forest areas from the world map created by Olson (1989-91), which displays 74 ecosystem categories across the globe within $.5^{0} \times .5^{0}$ and $10 \mathrm{~min} \times 10 \mathrm{~min}$ grid cells.
} 
net primary productivity (NPP) that results from climate change made us to observe the change in plant growth. Thus, we assumed that the growth per unit of time of trees is proportional to NPP. Letting $t=0$ for 1990 and $t=70$ for 2060, we linearlized the effects of climate change using

$$
\kappa_{h}(t)=1+\kappa \cdot t
$$

where $\kappa=\left(\frac{N P P_{70}}{N P P_{0}}-1\right) / 70$. The non-climate change yield function per hectare was

defined as $q_{h i j}=f_{h}\left(i, z_{h i j}\right)$ for land class $h$ in time period $j$ and the standing trees were regenerated $i$ years ago ${ }^{6}$

To capture the effects of NPP change, we modified the yield function for trees for the time period during which climate change occurs. To simplify this discussion we wrote the non-climate change yield function as

$$
q_{h i j}=\alpha e^{\frac{\beta}{i-\gamma}}
$$

and the growth due to aging of the tree is

$$
\frac{d q}{d i}=-\frac{\beta}{(i-\gamma)^{2}} \cdot \alpha \cdot e^{\frac{\beta}{(i-\gamma)}}
$$

\footnotetext{
${ }^{6}$ In this research, we used the yield function of tree formulated on " The Long Term Adequacy of World Timber Supply" by Sedjo and Lyon (1990) as non-climate change yield function. The non-climate change yield function of tree consists of functional components such as age of trees and management of practices (regeneration input). The non climate change yield function of tree is as follows;
}

$$
\begin{aligned}
& q=q^{1}(z) \cdot q^{2}(\text { age }) \\
& q^{1}(z)=(z+1)^{c^{1}} \quad \text { for } z \leq \bar{z} \\
& (z+1)^{c^{1}}+a z+b z^{2}+c \quad \text { for } z>\bar{z} \\
& \text { and } \\
& q^{2}(\text { age })=c^{2} \exp \left(c^{3}+c^{4} /\left(\text { age }-c^{5}\right)\right) \quad \text { for age }>c^{5} \\
& 0 \\
& \text { for } a g e \leq c^{5}
\end{aligned}
$$


On the other hand, while climate change is occurring $(j \in[1990,2060])$ the growth due to aging at year $j$ is given as

$$
\begin{aligned}
\frac{d \widetilde{q}}{d i} & =-\frac{\beta}{(i-\gamma)^{2}} \cdot \alpha \cdot e^{\frac{\beta}{(i-\gamma)}} \cdot(1+\kappa(i-a)) \\
& =-\frac{\beta}{(i-\gamma)^{2}} \cdot \alpha \cdot e^{\frac{\beta}{(i-\gamma)}}-\frac{\beta}{(i-\gamma)^{2}} \cdot \alpha \cdot \kappa(i-a) \cdot e^{\frac{\beta}{(i-\gamma)}}
\end{aligned}
$$

where $i=a+\left(j-j^{*}\right)$ and $a$ is the age of tree at year $j^{*}$ at which time climate change begins to occur; $1+\kappa(i-a)$ denotes the change of NPP during the time period of $j-j^{*}$. Thus, the yield function is the solution to the differential equation (13). In addition, the yield function for $j \in[2061, \infty]$ would be the solution to

$$
\frac{d \hat{q}}{d i}=-\frac{\beta}{(i-\gamma)^{2}} \cdot \alpha \cdot e^{\frac{\beta}{(i-\gamma)}} \cdot \bar{\kappa}
$$

where $\bar{\kappa}=1+\kappa \cdot 70=N P P_{70} N P P_{0}$. We used these yield functions to reflect the growth of tree associated with the increment of net primary productivity.

\section{SIMULATION RESULTS OF THE GLOBAL TIMBER MARKET}

To examine the impact of global warming on the global timber market, we simulated intertemporal values of endogenous variables for both the non-climate change base scenario and the climate change scenario under normal timber demand (ND) growth scenario over a time horizon of 90 years, starting in 1995. For the simulation of climate change scenario, we modified the TSM 2000 to reflect dynamic ecological change associated with climate change. The estimations obtained for both the base scenario and the climate change scenario allows us to predict the effect of global warming on the 
global timber market. In addition, to assess sensitivity of results to different assumptions of timber demand growth we also simulated the model under both high timber demand growth (HD) and very high timber demand growth (VHD) scenarios. We start with a brief overview of the underlying assumptions of the base scenario of the TSM 2000 under normal timber demand growth, and analyze simulation results of the base scenario and then the climate change scenario of TSM 2000 under a normal timber demand growth scenario

An Analysis of the Base Scenario

In our modeling framework, if there is no climate change, the base scenario outcomes are considered most presumable and will be used as the baseline to compare with and contrast against all other scenarios. The assumptions used for model simulation of the base scenario under normal demand scenario are as follows;

1. World demand schedule for industrial wood (combined pulpwood and solidwood products) will increase at an annual growth rate of $1.0 \%$ in the first year and decreases in a linear fashion each successive year until growth rate is zero in the 90th year.

2. World demand schedule for pulpwood initially increases at an annual growth rate of $2.27 \%$ in the first year and decreases in a linear fashion each successive year until the growth rate is zero in the 90 th year.

3. New forest plantations are established in the emerging region at a annual rate level of 2,80 million hectares for ten years. 
4. The dollar exchange rate is assumed to remain at an intermediate level throughout the period of analysis. ${ }^{7}$

In the formulation of TSM 2000 the former Soviet Union as well as plantation forests in India, African countries, and Asia Pacific were included as a part of responsive regions. As a result, we needed to estimate the new demand function for responsive regions. Due to this regional realignment, we considered the world timber demand function as the demand function for the responsive regions in TSM 2000. Initial total world timber demand is estimated by the following function;

$$
P=250-0.001215 \cdot Q
$$

We assumed that the initial demand portion of solidwood is $60 \%$ of the total world demand. On the basis of this portion, the initial solidwood and pulpwood demand functions were specified as follows;

$$
\begin{aligned}
& P^{s}=162-0.001215 \cdot Q^{s} \\
& P^{p}=118-0.001215 \cdot Q^{p}
\end{aligned}
$$

By extending land classes from 22 land classes contained in TSM to 42 land classes in TSM 2000, we needed to include not only the cost functions but also the yield functions for new land classes. Components of cost function for new land classes such as harvest, access, domestic and international transportation cost are estimated from the previous works of Sedjo and Lyon (1990) and Sohngen et al. (1996). Yield functions for the new land classes were selected to have the same basic equations as those in Sedjo and Lyon (1990). The coefficients of yield functions of new land classes were selected to

\footnotetext{
${ }^{7}$ These four conditions were also used in the analysis of the climate change scenario.
} 
reflect characteristics of the region such as climate and topography, in which each land class is located.

The variable proportions of production in solidwood, $\phi_{h}$, for new land classes were constructed from those given in Sedjo and Lyon (1996) by considering land classes with similar geographical characteristics, ecosystem type, climate, NPP, etc. In general, the annual market discount rate would fluctuate over the simulation period, but in this research we used $4 \%$ of fixed interest rate as annual discount rate for entire simulation time period. Given the initial commercial timber stock inventory for each land class, we simulated the base TSM 2000 scenario, and identified the optimal time profile of harvesting volumes and prices of solidwood and pulpwood, respectively. Simulation Results of the Base Scenario

Simulation results of the base scenario are shown in Figure 1 to Figure 4. Figure 1 shows that the total industrial wood production increases $31 \%$ from 1.59 billion cubic meters in 1995 to 2.08 billion cubic meters in 2085 . Figure 2 shows $55 \%$ increase of the volume of pulpwood production from 821 million cubic meters in 1995 to 1.28 billion cubic meters in 2085 . The estimate of pulpwood production suggests that $93 \%$ of increase in total industrial wood (455 million cubic meters) would be pulpwood and only $7 \%$ of increase in total industrial wood would be solidwood production over the 90 years. This suggests that the large portion in the composition of industrial wood would be shifted away from solidwood to pulpwood in order to accommodate the more rapidly rising demand growth in pulpwood. Figure 3 , hence, shows that the solidwood increases $4.6 \%$ from 765 million cubic meters in 1995 to 800 million cubic meters in 2085. Figure 4 shows estimated price changes for solidwood and pulpwood over the simulation period. 
The prices for pulpwood and solidwood experience increasing trend over the simulation period: the price of pulpwood increases $44 \%$ from $\$ 43$ in 1995 to $\$ 62$ in 2085 while the price of solidwood increases $21 \%$ from $\$ 76$ in 1995 to $\$ 92$ in 2085. The faster rise of pulpwood price is due to higher demand growth for pulpwood relative to solidwood. This relative price increase of pulpwood signals producers to switch away more industrial wood production from solidwood to pulpwood.

Simulation of timber production by regions suggests that the dominant production regions currently, and in 2085, are in the emerging region, the U.S South, and East Siberia. Over 90 years, the emerging region increases production by a factor of three while the U.S South and the East Siberia regions roughly double their timber production. Most timber production of these regions contributes to the increase of pulpwood production. Eastern Canada and European USSR also increase timber production, mostly in supplying pulpwood. Nordic Europe maintains fairly substantial timber production over the first 70 years and after that timber production declines slightly. The change of timber production patterns in Nordic Europe suggests that a fairly substantial amount of discuss the timber production over early period is a result of matured postwar regenerated trees being harvested (Sedjo and Lyon, 1990). However, declining timber production after year 70 is due to the fact that standing matured second growth trees are not sufficient to maintain the harvest level even though timber demand grows. The U.S Pacific Northwest, Western Canada, West Siberia, and Asia Pacific are only modest producers of timber, and experience a minimal change over the 90 years period. Prior to the initial simulation year, both the U.S Pacific Northwest and Western Canada experienced increasing government oversight directed at withdrawal of forests on public 
lands. These conservation efforts will only allow these regions to show the modest timber production over the entire simulation period.

An Analysis of the Climate Change Scenario

In order to identify how global warming affects the global timber market, we modified the TSM 2000 on the basis of estimated magnitudes of dynamic ecological change. Modification of TSM 2000 included the law of motion of the hectares of trees by age and the harvesting volume of trees for each land class. First, we will discuss the modification in the law of motion of hectares of trees by age. Modification in the law of motion of hectares of trees by age required explicit characterization of how global warming transforms the distributions of ecosystem type during the transient time period. The distributions of ecosystem type were changed in accordance with two dynamic ecological processes: dieback and regeneration. In this context, land area of ecosystem type was subdivided into two mutually exclusive areas: the area where standing trees were expected to die out, and the area where the standing trees were expected not to die out.

For the land areas where standing trees were expected to die out, the dieback hectares per year on the basis of estimated dieback ratio for each land class were calculated. With this result, we were also able to calculate the ratio of dieback area to total commercial land area for each year during the transient time period. The ratio of dieback area to the total commercial land area for land class in year $j$ was denoted as

$$
\frac{\text { dieback per year }_{h}}{\sum x_{h, i, j}}, \quad \text { for } i=2,3, \ldots \ldots M \text {. }
$$

Thus, equation (8a), which denoted the law of motion of the hectares of trees by age, was changed as following equation, 


$$
x_{h, j+1}=\left(C+D U_{h j}\right) x_{h, j} \quad \text { for all } h, j
$$

where

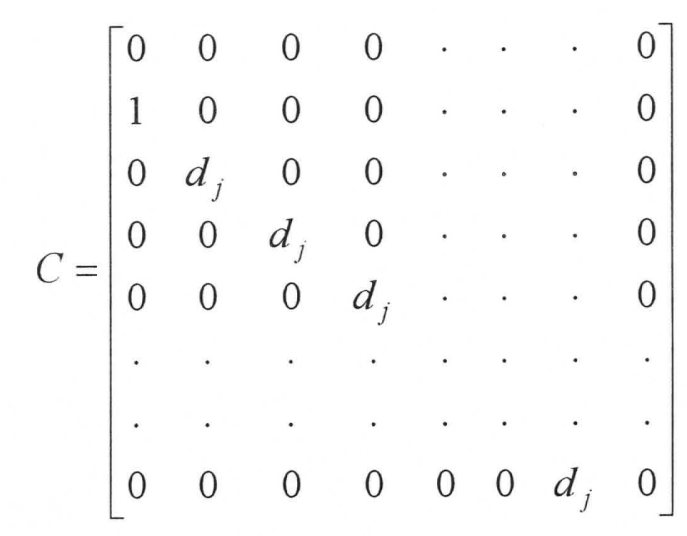

$$
D=\left[\begin{array}{cccccccc}
d_{j} & d_{j} & d_{j} & d_{j} & . & . & . & d_{j} \\
0 & 0 & 0 & 0 & . & . & . & 0 \\
0 & -d_{j} & 0 & 0 & . & . & . & 0 \\
0 & 0 & -d_{j} & 0 & . & . & . & 0 \\
0 & 0 & 0 & -d_{j} & . & . & . & 0 \\
\cdot & \cdot & . & \cdot & . & . & . & \cdot \\
. & \cdot & . & . & . & . & . & . \\
0 & 0 & 0 & 0 & 0 & 0 & -d_{j} & 0
\end{array}\right]
$$

and $\quad d_{j}=1-\frac{\text { dieback per year }_{h}}{\sum x_{h, i, j}}$, for $i=2,3, \ldots \ldots M$

This equation can also be expressed as

$$
\begin{array}{ll}
x_{h, 1, j+1}=d_{j} u_{h, j}^{\prime} x_{h, j} & \\
x_{h, 2, j+1}=x_{h, 1, j} & \text { for all } h, j \\
x_{h, i+1, j+1}=d_{j}\left(x_{h, i, j}-u_{h, i, j} x_{h, i, j}\right) & (i=2,3, . .
\end{array}
$$

For the land areas where standing trees were expected not to die out, equation (8a) was, also, changed as 


$$
x_{h, j+1}=\left(A+B U_{h j}\right) x_{h j}+\left(v_{h j}+R R_{h}\right) e \quad \text { for all } h, j
$$

where $R R_{h}$ denotes the regeneration hectares per year for land class $h$, and $A, B, U_{h j}, v_{h j}$, and $e$ are the same as defined in the equations (8a) and (8b).

This equation can be expressed as

$$
\begin{array}{ll}
x_{h, 1, j+1}=u_{h j}^{\prime} x_{h j}+v_{h j}+R R_{h} & \text { for all } h, j \\
x_{h, i+1, j+1}=x_{h, i, j}-u_{h, i, j} x_{h, i, j} & (i=1,2, \ldots \ldots \ldots \ldots, M-1)
\end{array}
$$

Next, the volume of commercial timber harvested for the total industrial wood after climate change was modified by identifying three harvesting categories. The first category is where commercial harvesting occurs in the land areas in which standing trees were expected to die out after climate change. The second category accounts for the possibility that some portion of dieback trees were salvaged from dieback areas. The third category considers commercial harvesting in the land areas in which standing trees were expected not to die out after climate change. For the salvage of dieback trees, the salvage rate of dieback trees was assumed to be $60 \%$ of normal merchantable volume on average for both accessible and inaccessible land areas, and $70 \%$ of merchantability ratio for all salvage operations. ${ }^{8}$ The merchantability ratio is defined as the minimum age of salvage trees divided by the optimal harvest age.

At year $j$, the three cases of commercial harvesting volume were specified as follows: Commercial harvesting volume in the land area in which standing trees were expected to die out after climate change is

$$
u_{h j}^{\prime} d_{j} X_{h j} q_{h j} \quad \text { for all } h, j
$$


where $X_{h j}$ is a diagonal matrix using the elements of $x_{h j}$, the vector of hectares of trees in this land area; $q_{h j}$ is the vector of non-climate change yield function (See equations in footnote 6). Salvage volume of dieback trees is

$$
s\left(1-d_{j}\right) \cdot \sum_{i=k}^{M} x_{h, i, j} q_{h, i, j} \quad \text { for all } h, j
$$

where $s$ is the salvage rate, and age $k$ is the margin for the salvage of dead trees ${ }^{9}$.

Commercial harvesting volume in the land area in which standing trees were expected not to die out after climate is

$$
u_{h j}^{\prime} X_{h j} \widetilde{q}_{h j} \quad \text { for all } h, j
$$

where $\widetilde{q}_{h j}$ is the vector of modified yield function of trees when climate change occurs (See equation (13)). The total volume harvested of industrial wood after climate change is the sum of harvesting volume of these three cases. Harvesting volume for solidwood was calculated by multiplying the total harvested volume of industrial wood by $\phi_{h}$ while harvesting volume for pulpwood was calculated by multiplying the total harvest volume of industrial wood by $\left(1-\phi_{h}\right)$.

\section{Simulation Results of the Climate Change Scenario}

Output projections of climate change scenario are shown in Figures 5 to 7 . Figure 5 reveals that total industrial wood production increases from 1.64 billion cubic meters in 1995 to 2.70 billion cubic meters in 2085 . The increment of total industrial wood is 1.06 billion cubic meters (65\% increase) over the entire simulation period. Relative to the

\footnotetext{
${ }^{8}$ In reality, both salvage rate and the merchantability ratio are not fixed as we assumed here, but they change as timber prices change. To simplify the analysis of salvage of dead trees after climate change, we assumed that both ratios are fixed.

${ }^{9}$ Age $k$, i.e., the marginal age for the salvage of dead trees, are identified through the merchantability ratio if the optimal harvesting age is determined in the land area where standing trees are expected to die out.
} 
base scenario, production is larger by 625 million cubic meters in 2085, and it reflects 30 $\%$ larger production than in the base scenario. Estimated gains in timber production due to climate change are the result of two important factors: first, BIOME 3 predicts an increase in net primary productivity for all land classes, and second BIOME 3 predicts that there will be an increase in hectares of faster growing tree species. As a result, the climate change scenario shows global timber supply grows faster than global timber demand, resulting in declining timber prices.

Specifically, Figure 6 shows that the volume of pulpwood will increase from 846 million cubic meters in 1995 to 1.54 billion cubic meters in 2085. This increment of pulpwood production will be 694 million cubic meters over the entire simulation period. In the climate change scenario pulpwood production in 2085 is 261 million cubic meters larger than in the base scenario. Figure 7 shows the volume of solidwood production increasing from 793 million cubic meters in 1995 to 1.16 billion cubic meters in 2085 . Solidwood production in the base scenario shows only modest gains; however, in the climate change scenario, production gains are larger. Estimates for the climate change scenario indicate that solidwood production in 2085 is 364 million cubic meters larger than in the base scenario. Figure 8 shows that the supply response induces a substantial price decrease for both solidwood and pulpwood. Solidwood price is estimated to decrease about $34 \%$ from $\$ 73$ per cubic meter in 1995 to $\$ 48$ in 2085 . Pulpwood price will decrease about $25 \%$ from $\$ 40$ in 1995 to $\$ 30$ in 2085 . This simulation suggests that the global warming will have a positive effect on the global timber market through increasing timber production, and decreasing the prices of solidwood and pulpwood 
Regional variation in timber production suggests some differences relative to the base scenario. The dominant production region over 90 years is East Siberia, followed by the U.S South and the emerging region. In East Siberia, the total volume of industrial wood increases $107 \%$ from 413 million cubic meters in 1995 to 854 million cubic meters in 2085. Unlike the base scenario, this region has an increase in the production for both pulpwood and solidwood. The volume of pulpwood and solidwood increase 267 million cubic meters and 174 million cubic meters, respectively. In the U.S South, the total volume of industrial wood increases $126 \%$ from 268 million cubic meters in 1995 to 605 million cubic meters in 2085. The volume of pulpwood and solidwood increases 196 million cubic meters and 142 million cubic meters, respectively. In the emerging region, the total volume of industrial wood increases $29 \%$ from 435 million cubic meters in 1995 to 562 million cubic meters in 2085. The volume of pulpwood and solidwood increase 92 million cubic meters and 34 million cubic meters over the simulation period, respectively. The increment of timber production in the emerging region after climate change is relatively less than in the other dominant region. Also, most of the production increase in total industrial wood is in pulpwood. Unlike other dominant regions, the increase in production of solidwood in the emerging region is very modest.

Regional production estimates imply that East Siberia and the U.S South are greatly impacted by the global warming, mostly through the increase in hectares of faster growing species, and the increase in NPP. In these regions, global warming increases timber production for both pulpwood and solidwood. Although the emerging region is also impacted by climate change, timber production in this region is predominantly used for pulpwood rather than solidwood because of the regional characteristics that plants that 
have short rotation and fast growing trees (Sedjo 1995). Other regions also show that pulpwood and solidwood production increase over the entire simulation period. Both Eastern Canada and European USSR show substantial timber production over 90 years. Nordic Europe shows a fairly substantial timber production over earlier simulation time period, but since then timber production decreases to 2085 as in the base scenario. The remaining regions show modest increase of timber production as discussed in the base scenario.

\section{A Sensitivity Analysis of Timber Demand Growth Scenarios}

We analyzed model results under two different timber demand scenarios; high timber demand growth scenario and very high timber demand growth scenario. The high timber demand growth scenario is mainly based on recent FAO forecasts. The FAO forecasted the demand of total industrial wood to increase by $1.8 \%$ annually and pulpwood to increase at a rate of $2.5 \%$ annually to the year 2010 . For this research, we extended the growth period to 2085 , with the timber demand growth declining linearly to zero in 2085 . For the very high timber demand growth scenario, we took into account the growth rate of demand as twice that of the FAO forecasts. In this case, the total industrial wood demand initially grows at $3.6 \%$ annually, and pulpwood demand growth increases initially $5.0 \%$ annually to the year 2085 , both will decline linearly to zero at the end of 90 years in year 2085. The simulation results of the base scenario and the climate change scenario under high timber demand growth scenario and very high timber demand growth scenario are given in Table 1 and Table 2, respectively. According to Tables, the trends of timber production and timber prices suggest that the climate change also have a positive impact on the global timber supply. 
These sensitivity analyses provide significant information on the direction, magnitude, and natures of various adjustment mechanisms in the global timber market. In summary, the economic system responded to increasing growth of timber demand through changes in timber production and prices. Differences in timber production and prices are highly related with differences in the growth rate of timber demand, and in the potential capacity to produce and expand available supply. Also, if growth of pulpwood demand increases at a significantly higher rate than solidwood demand, the production of solidwood increases at a very modest rate or decreases in the later part of simulation period. This trend results from the fact that higher growth of pulpwood demand relative to solidwood demand switches industrial wood from solidwood to pulpwood. Finally, if timber demand grows at a higher rate than that in normal demand scenario, the initial timber production is lower, but timber production is ultimately larger than in normal timber demand scenario. This structure suggests that rational forward-looking producers postpone the initial timber production with the anticipation of higher price in the future. An Analysis of Welfare Change in Timber Market

In order to examine the effect of global warming on the global timber market in the economic welfare sense, we measured the welfare change between the base scenario and the climate change scenario under each of timber demand scenario. As already stated, the welfare level in TSM 2000 is the sum of discounted present value of net surplus over the simulation period. Suppose that the optimal volume of timber production for solidwood and pulpwood in year $j$ is $Q_{j}^{*}$ and $\widetilde{Q}_{j}^{*}$. Then the net surplus at optimum in year $j$ is 


$$
s_{j}=\int_{0}^{Q_{j}^{*}} D_{j}^{s}(n) d n+\int_{0}^{\widetilde{Q}_{j}^{*}} D_{j}^{p}(n) d n-C_{j}^{*}
$$

and the sum of discounted present value of net surplus at optimum over the simulation period is

$$
S_{0}^{*}\left(x_{0}, z_{0}, u, w\right)=\sum_{k=0}^{J-1} \rho^{k} s_{k}^{*}+\rho^{J} S_{J}^{*}\left(x_{J}, z_{J}\right)
$$

where $k=0$ for year 1995 and $k=J$ for year 2085 .

Under the normal timber demand growth scenario, we calculated the welfare levels for both the base scenario and the climate change scenario. The total discounted present value of net surplus (the welfare level) for the base scenario is about 336 million dollars while that for the climate scenario is about 352 million dollars. The welfare level in the climate change scenario is 16 million dollars (4.8\%) larger than in the base scenario. This amount of welfare increase suggests that the society will experience an economic benefit through the global timber market when climate change occurs.

Under the high timber demand growth scenario, the welfare level for the base scenario is about 385 million while that for the climate change scenario is about 450 million dollars. The welfare level in the climate scenario is about 65 million dollars (16.9 $\%$ ) larger than in the base scenario. Also, under the very high timber demand growth scenario, the welfare level for the base scenario is 750 million dollars while that for the climate scenario is 878 million dollars. The welfare level in the climate scenario is about 128 million dollars $(17.1 \%)$ larger than in the base scenario. These amounts of welfare increase in both timber demand scenarios indicate that the global warming is economically beneficial to society through the global timber market.

\section{CONCLUSION}


Using dynamic integrated models of ecosystem and economic system that arise from prediction of global warming, we identified that global warming has a positive impact on the global timber market through increase of timber productions and decrease of timber prices of solidwood and pulpwood. Also, in the welfare sense, we examined that global warming is economically beneficial to society through the global timber market. There are many avenues for future research. We feel that the most promising would be to identify the sensitivity of these results to the ecological and general circulation models used.

\section{REFERENCES}

Adams, D.M, J.A. Ralph, B.A. McCarl, J.M. Callaway, and S.M. Winnett, 1996, "An Analysis of the Impacts of Public Timber Harvest Policies on Private Forest Management in the United States". Forest Science, 42 (3): p 343- 358.

Backman, C.A, and T.R. Waggener, 1991, Soviet Timber Resources and Utilization: An Interpretation of the 1988 National Inventory. CINTRAFOR Working Paper 35, Center for International Trade in Forest Products, University of Washington, Seattle.

Berck, P., 1979, "The Economics of Timbers: A Renewable Resource in the Long Run", Bell Journal of Economics, 10: p 447-462.

Binkley, C.S., 1988, "A Case Study of the Effects of $\mathrm{CO}_{2}$-induced Climatic Warming on Forest Growth and the Forest Sector: B. Economic Effects on the World's Forest Sector" in The Impact of Climate Variations on Agriculture, Eds. Parry, M. L., Carter, T.R., and Konjin, N.T., Kluwer, Dordrecht.

Brazee, R., and R. Mendelsohn, 1990, " A Dynamic Model of Timber Markets", Forest Science, vol 36 (2): p 255-264.

Burton, D.M, B.A. McCarl, N.M. de Sousa, D.M. Adams, R.A. Alig, and S.M. Winnett, 1998, " Economic Dimensions of Climate Change Impacts on Southern Forests", Ecological Studies, 128: p 777-794 and in The Productivity and Sustainability of Southern Forest Ecosystems in a Changing Environments, Eds. Fox, S and Mickler, R., New York: Spring Verlag. 
Claussen, M., 1996, " Variability of Global Biome Patterns as a Function of Initial and Boundary Conditions in a Climate Model, Climate Dynamics, 12: p 371-379.

Halkin, H., 1966, " A Maximum Principle of the Pontryagin Type for Systems Described by Nonlinear Difference Equations", Journal of SIAM control, vol 4 (1): p 90-111.

Haxeltine, A. and I.C. Prentice, 1996, "BIOME3: An Equilibrium Terrestrial Biosphere ModelTotal Land (Base d on Ecophysiological Constraints, Resource Availability, and Competition Among Plant Functional Types". Global Biogeochemical Cycles. 10(4):693709.

Intergovernmental Panel on Climate Change (IPCC), 1990, Climate Change: The IPCC Scientific Assessment, edited by J. T. Houghton, G.J. Jenkins, and J.J. Ephraums, Cambridge, England, Cambridge University Press.

IUCN, 1994, 1993, United Nations List of National Parks and Protected Areas, International Union for Conservation of Nature and Natural Resources, Gland, Switzerland and Cambridge, UK.

Joyce, L.A, J.R. Mills, L.S. Heath, A.D. McGuire, R.W. Haynes, and R.A. Birdsey, 1995, " Forest Sector Impacts from Changes in Forest Productivity Under Climate Change", Journal of Biogeography, 22: p 703-713.

King, G. A., R.P. Neilson, 1992, " The Transient Response of Vegetation to Climate Change: A Potential Source of $\mathrm{CO}_{2}$ to the Atmosphere", Water, Air, and Soil Pollution, 94: p 365383.

Lyon, K.S and R.A. Sedjo, 1992, "Comparative Advantages in Timber Supply: Lessons from History and the Timber Supply Model, p 171-186 in Emerging issues in forest poicy, Nemetz, P.N.(ed.), University of British Columbia Press, Vancouver, Canada, 573p.

Mellilo, J., D. McGuire, D.M. Kicklighter, III, C. Vorosmarty, and A. Schloss, 1993, "Global Climate Change and Terrestrial Net Primary Production". Nature 363:p 234-40.

Neilson, R.P. and D. Marks, 1994, "A Global Perspectives of Regional Vegetation an Hydrologic Sensitivities from Climate Change". Journal of Vegetation Science. 5: p 715-730.

Olson, J.S., 1989-1991, World Ecosystem (WE 1.3 and WE 1.4), Digital Raster Data on Global Geographic (Lat/Lon) $180 \times 360$ and 1080 × 2160 grids, NOAA National Geophysical Data Center, Boulder, Colorado.

Parton, W.J., J.W.B. Stewart, and C.V. Cole, 1988, "Dynamics of C,N,P and S in Grassland Soils: A Model". Biochemistry, 5:p 109-31. 
Perez-Garcia, J., L.A Joyce, A.D. McGuire, and C.S. Binkley, 1997, "Economic Impact of Climate Change on the Global Forest Sector" in Economics of Carbon Sequesteration in Forestry, Eds. Sedjo, R.A., R.N. Sampson and J. Wisniewski, Lewis Publishers, Boca Raton.

Prentice, C., W. Cramer, S. Harison, R. Leeman, R. Monserud, and A. Solomon, 1992, "A General Biome ModelTotal Land (Based on Plant Physiology and Dominance, Soil Properties and Climate". Journal of Biogeography, 19:p 117-34.

Pontryagin, O.L., V.G. Boltyanskii, R.V. Gamkrelidze, and E.F. Mishchenko, 1962, The Mathematical Theory of Optimal Processes, NewYork, Interscience, translated by K.N. Trirogoff from Russian Origin.

Running, S.W. and S.T. Grower, 1991, "FOREST BGC, A General Model of Ecosystem Processes for Regional Applications. II. Dynamic Carbon Allocation and Forest Nitrogen Budgets". Tree physiology, 99: p147-60.

Running, S.W. and J.C. Coughland, 1988, " A General Model of Ecosystem Processes for Regional Applications. I. Hydrologic Balance, Canopy Gas Exchange and Primary Productivity Process". Ecological Modeling, 42: p 125-54.

Sedjo, R.A, 1995, "The Potential of High-Yield Plantation Forestry for Meeting Timber Needs: Recent Performance and Future Potentials", Discussion Paper 95-08, Resource for the Future, Washington, D.C.

Sedjo, R.A., and K.S. Lyon, 1990, The long-Term Adequacy of World Timber Supply. Resource for the Future, John Hopkins Press.

Sedjo, R.A., and K.S. Lyon, 1996, " Timber Supply Model 96: A Global Timber Supply Model with a Pulpwood Component", Discussion Paper 96-15, Resource for the Future, Washington, D.C.

Shugart, H.H., M.Y. Antonovsky, P.G. Jarvis, and A.P. Sandford, 1986, "CO 2 , Climate Change, and Forest Ecosystems" Chapter 10 in The Greenhouse Effect, Climatic Change and Ecosystems, Eds. Bolin, B., Doos, B. R., Jager, J., and Warrick, R.A., Chichester: Wiley.

Sohngen, B., R. Sedjo, R. Mendelsohn, K. Lyon, 1996. "A Global Timber Market Model". Mimeo, Department of Economics, Utah State University.

Sohngen, B.L., R. Sedjo, R. Mendelsohn, K.Lyon, 1997, "Climate Change Impacts: The Case of Global Timber Markets". Sumitted paper to the Annual Meetings of the American Agriculture Economics Association.

Sohngen, B. and R. Mendelsohn, 1998, "Valuing the impact of Large-Scale Ecological Change in a Market: The Effect of Climate Change on U.S. Timber", American Economic Review, vol 88 (4): p686-710. 
Sohngen, B.L, R. Mendelsohn, and R. Sedjo, 1999, " Forest Management, Conservation, and Global Timber Markets", American Journal of Agricultural Economics, Feb 1999: p1-13.

Solomon, A, M., 1986, " Transient Response of Forest to $\mathrm{CO}_{2}$-induced Climate Change: Simulation Modeling Experiments in Eastern North America", Oecologia, 68: p 567-579.

United Nations Food and Agricultural Organization (UNFAO), 1993a, Forest Resource Assessment 1990:Tropical Countries. Forestry Paper 112, Rome.

United Nations Food and Agricultural Organization (UNFAO), 1993b, Forestry Policies of Selected Countries in Asia and the Pacific. Forestry Paper 115, Rome.

United Nations Food and Agricultural Organization (UNFAO), 1995, Forest Resource Assessment 1990: Global Synthesis. Forestry Paper 124, Rome

Woodward, F.I., T.M. Smith, and W.R. Emanuel, 1995, " A Global Land Primary Productivity and Phytogeography Model". Global Biogeochemical Cycle, 9 (4): p 471-90.

Yan, M, 1996, The Impact of Conservation of Forests on Timber Production and Environment: Application of the Timber Supply Model. Unpublished Dissertation, Economics Department, Utah State University. 
Fig 1 Total Volume

[ND Base Scenario]

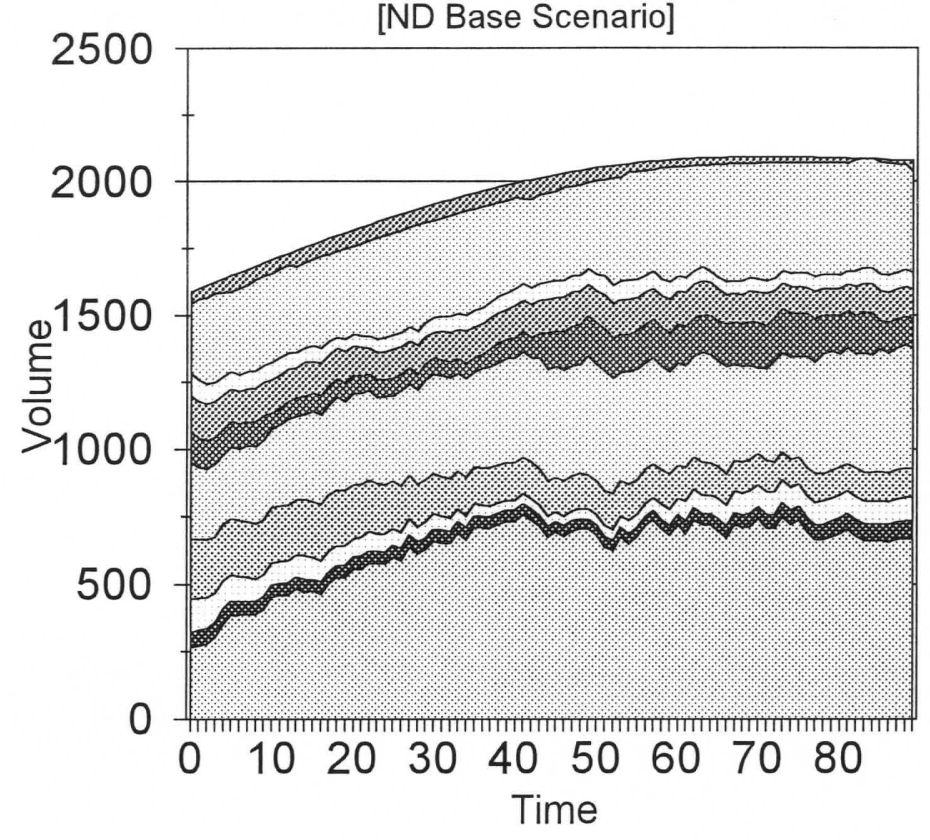

Fig 2 Pulpwood Volume [ND Base Scenario]

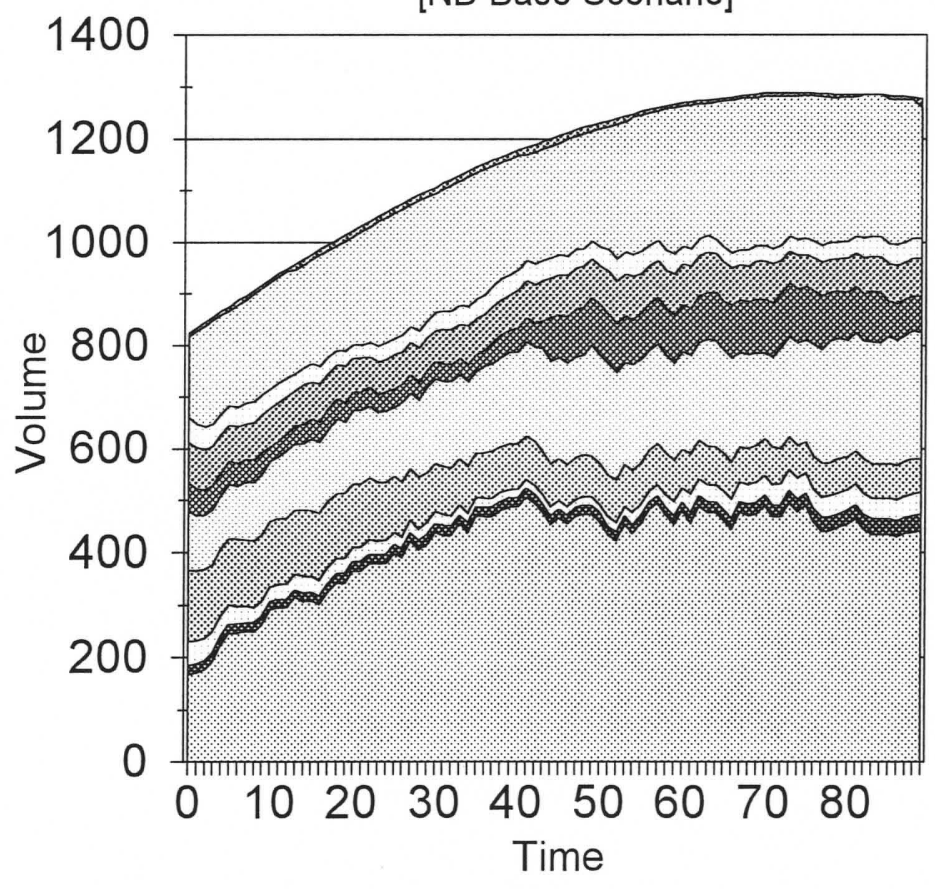

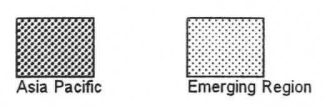

East Siberia

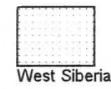

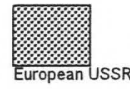
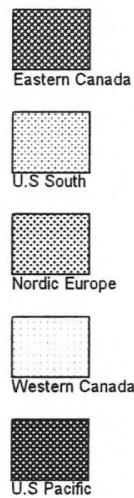
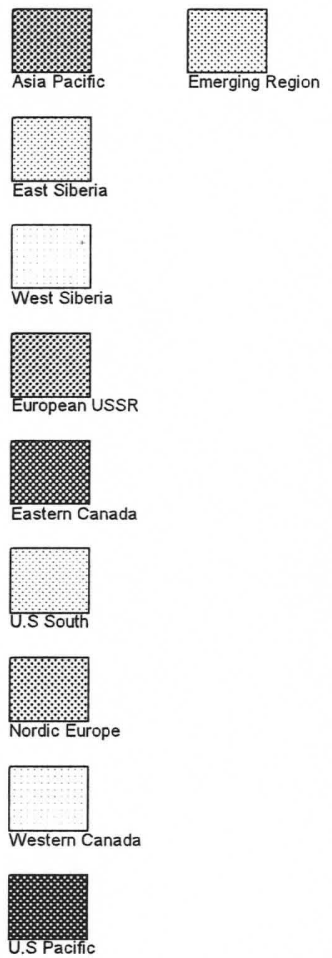
Fig 3 Solidwood Volume
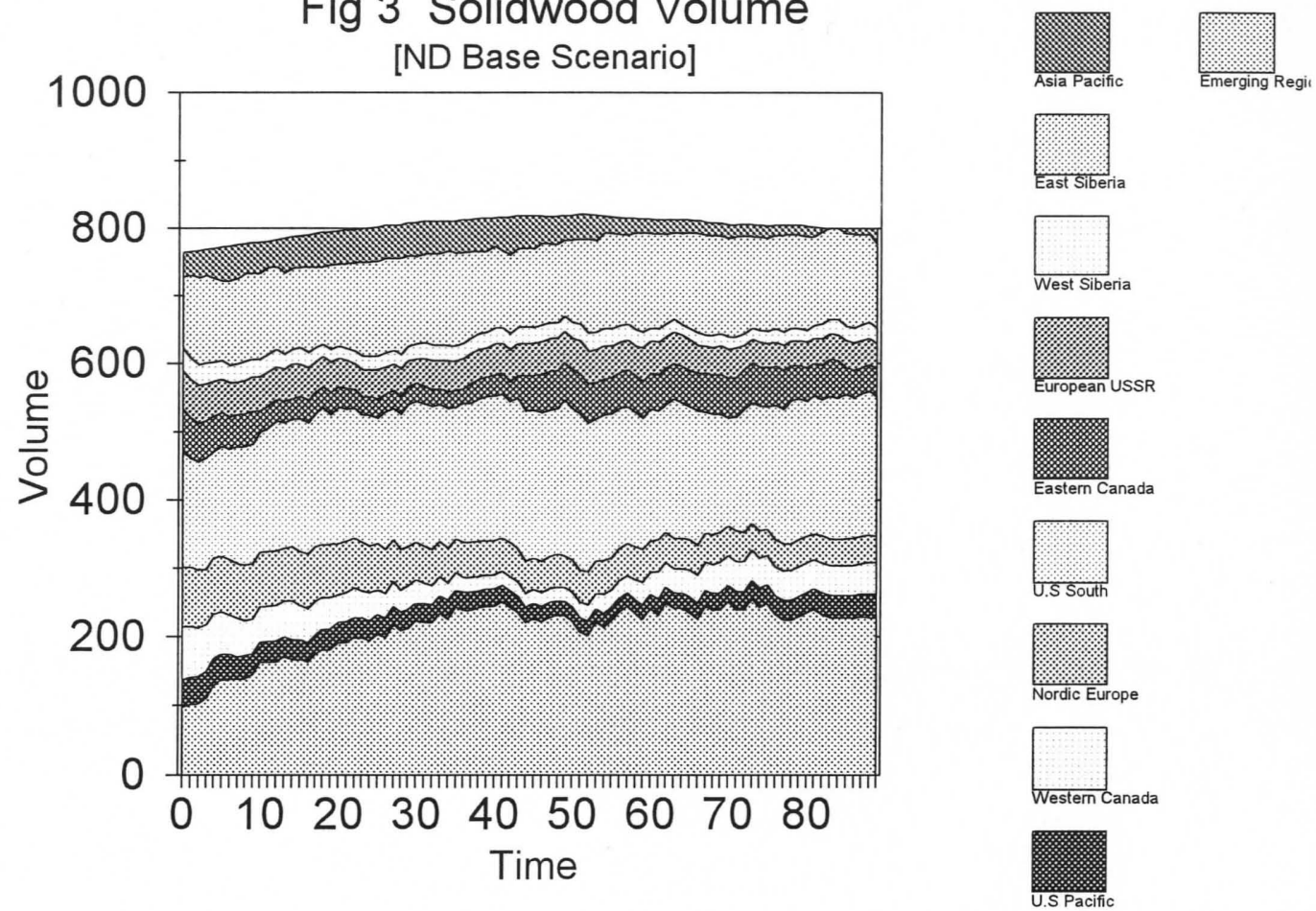

Fig 4 Timber Prices

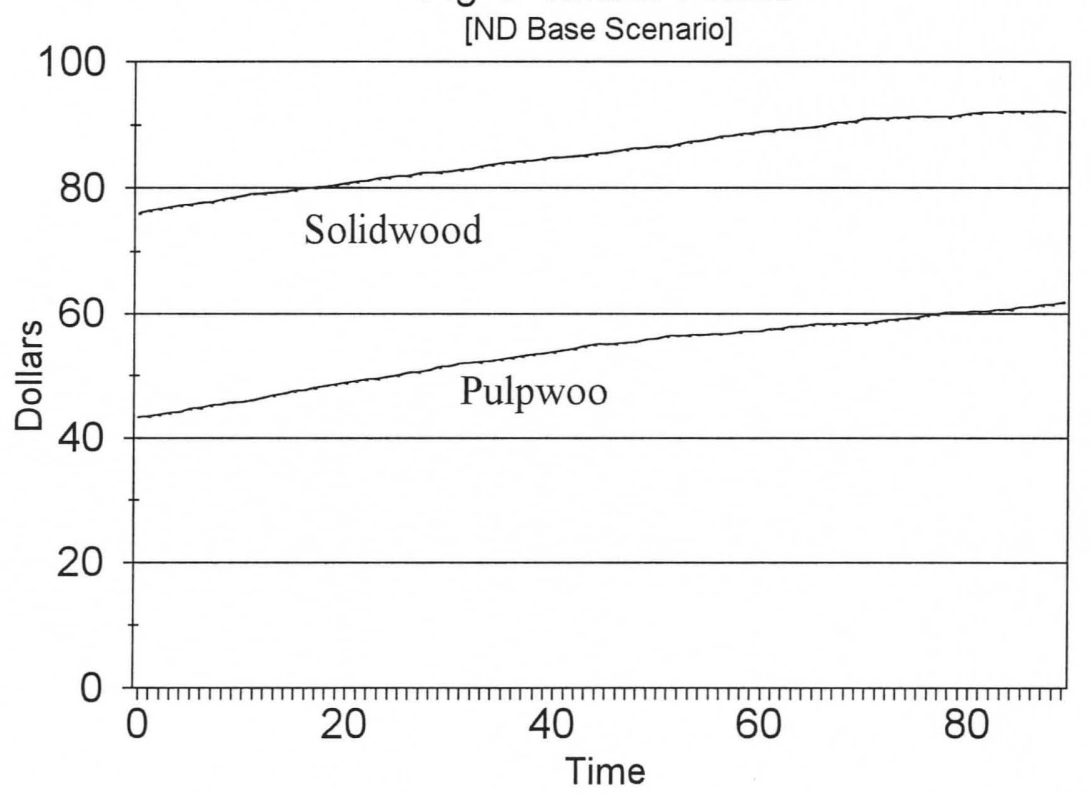


Fig 5 Total Volume [ND Climate Change Scenario]

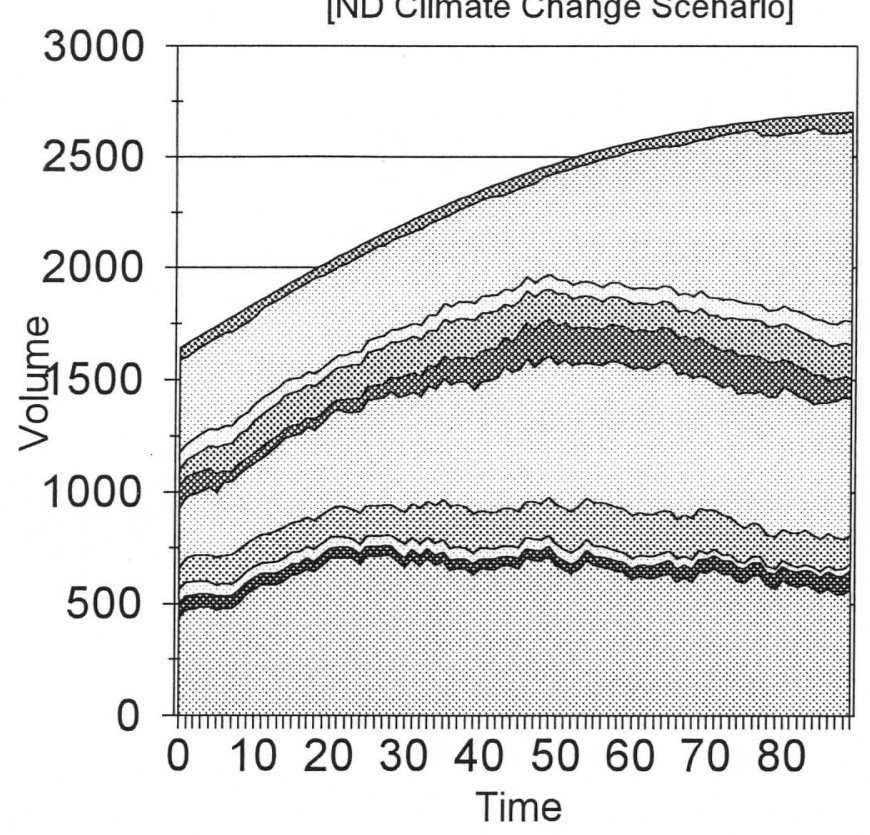

Fig 6 Pulpwood Volume

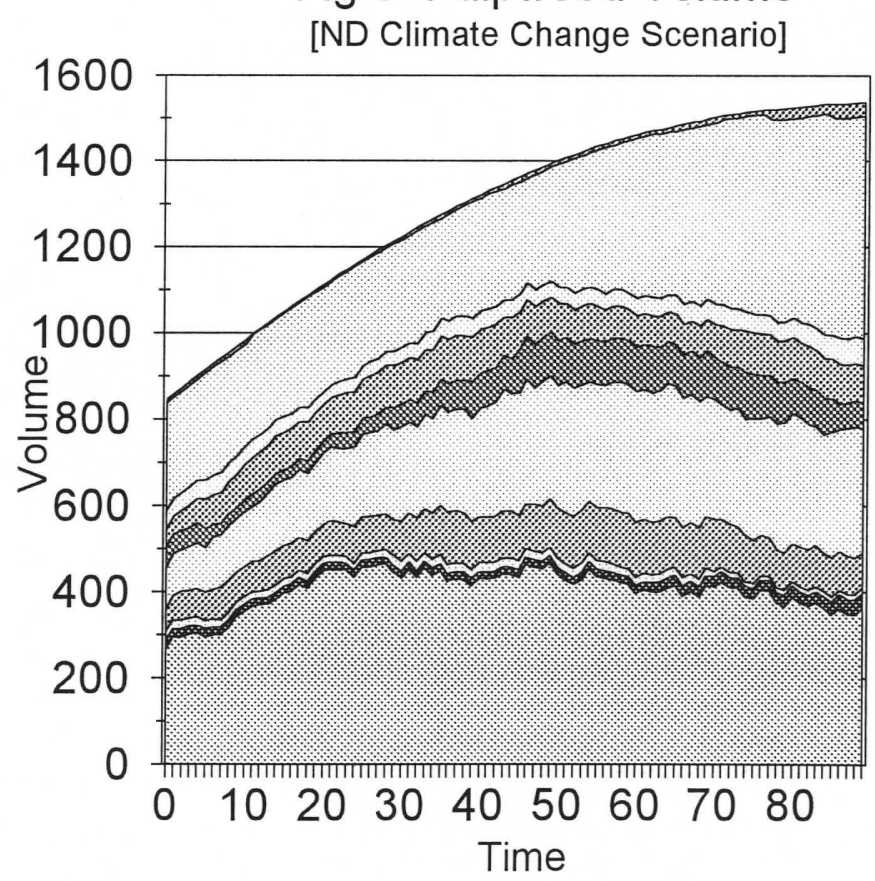

兹細
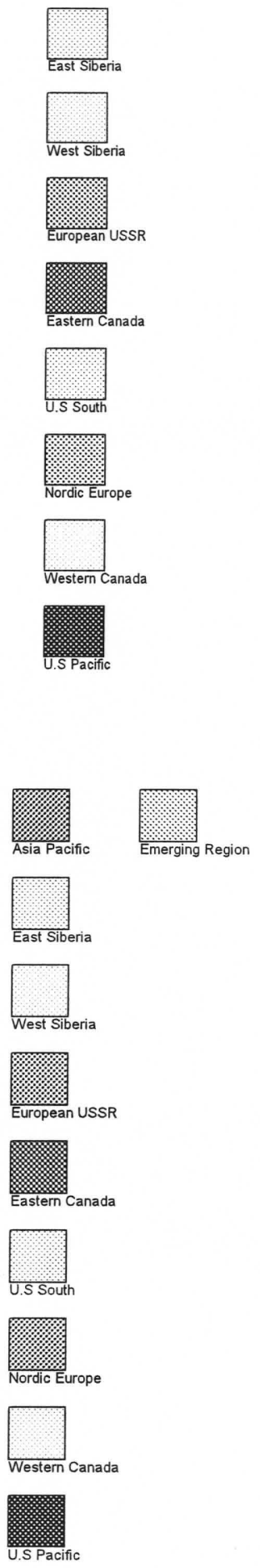
Fig 7 Solidwood Volume [ND Climate Change Scenario]
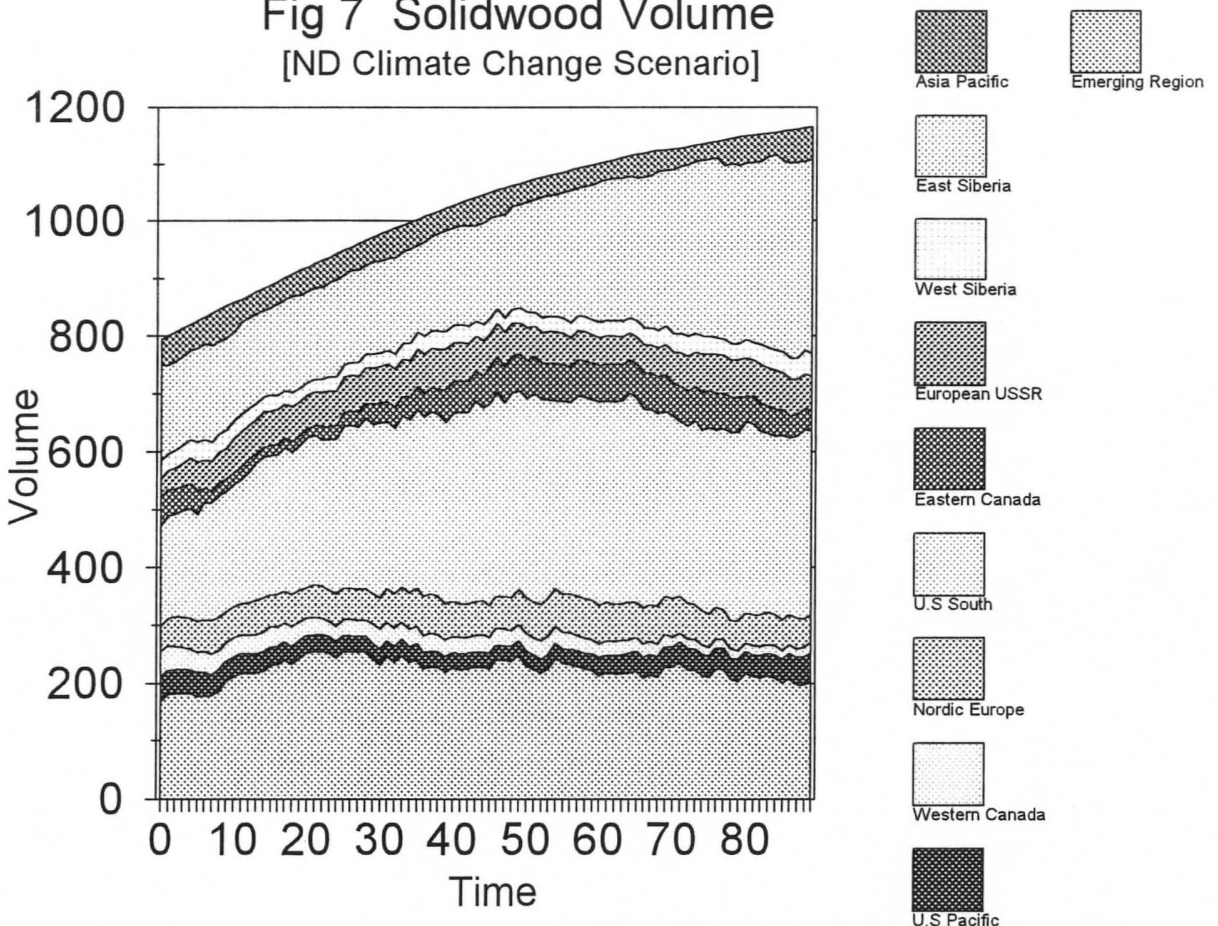

Fig 8 Timber Prices

[ND Climate Change Scenario]

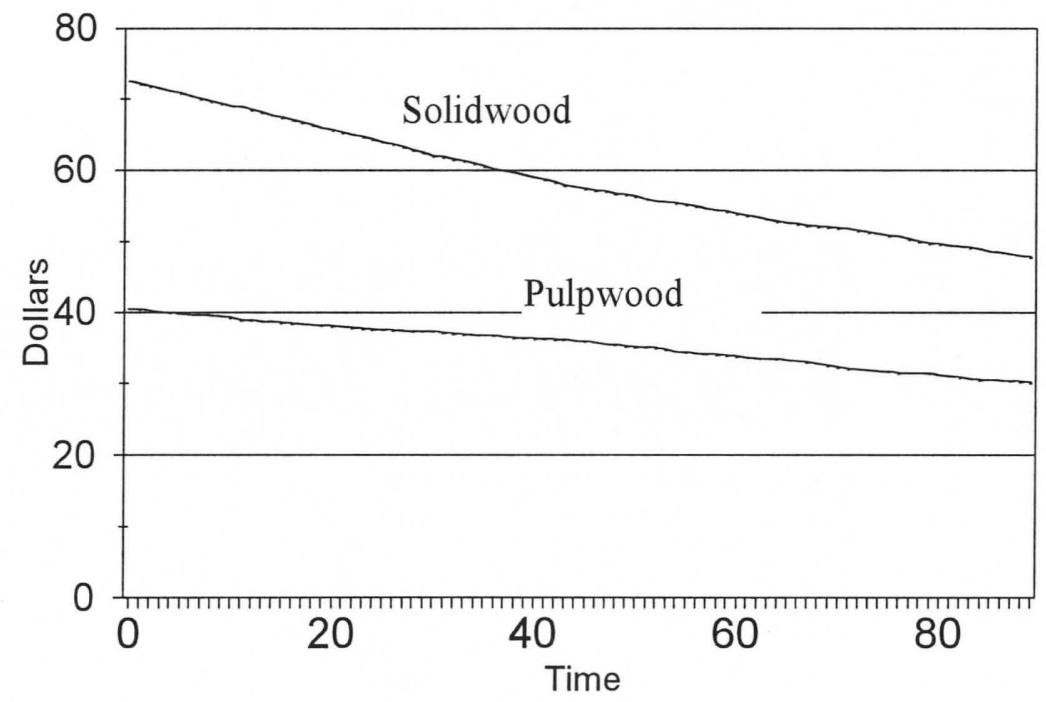


Table 1. Simulation Results of High Timber Demand Growth Scenario

\begin{tabular}{|c|c|c|c|c|}
\hline & \multicolumn{2}{|c|}{$\begin{array}{c}\text { Base } \\
\text { Scenario }\end{array}$} & \multicolumn{2}{|c|}{$\begin{array}{c}\text { Climate } \\
\text { Change Scenario }\end{array}$} \\
\hline & 1995 & 2085 & 1995 & 2085 \\
\hline Total volume & 1,150 & 2,180 & 1,390 & 3,470 \\
\hline Solidwood volume & 484 & 759 & 645 & 1,473 \\
\hline Pulpwood volume & 665 & 1,420 & 750 & 2,015 \\
\hline Solidwood price & 126 & 166 & 107 & 81 \\
\hline Pulpwood price & 76 & 125 & 64 & 53 \\
\hline Welfare Level & \multicolumn{2}{|c|}{385} & \multicolumn{2}{|c|}{450} \\
\hline
\end{tabular}

Note: 1) Unit of harvested volume is million cubic meters.

2) Unit of price is dollars and welfare level is million dollars.

Table 2. Simulation Results of Very High Timber Demand Growth Scenario

\begin{tabular}{|c|c|c|c|c|}
\hline & \multicolumn{2}{|c|}{$\begin{array}{c}\text { Base } \\
\text { Scenario } \\
\end{array}$} & \multicolumn{2}{|c|}{$\begin{array}{c}\text { Climate } \\
\text { Change Scenario }\end{array}$} \\
\hline & 1995 & 2085 & 1995 & 2085 \\
\hline Total volume & 1,740 & 2,710 & 2,880 & 4,190 \\
\hline Solidwood volume & 761 & 741 & 529 & 1,420 \\
\hline Pulpwood volume & 943 & 1,970 & 780 & 2,780 \\
\hline Solidwood price & 137 & 430 & 166 & 368 \\
\hline Pulpwood price & 81 & 409 & 101 & 292 \\
\hline
\end{tabular}

Note: 1) Unit of harvested volume is million cubic meters.

2) Unit of price is dollars and welfare level is million dollars. 
A Dynamic Analysis of the Global Timber Market under Global Warming: An Integrated Modeling Approach

\author{
DUG MAN LEE \\ Lecturer, Ph.D \\ Department of Economics \\ Pusan National University \\ Pusan, Korea \\ Tel) 82-2-692-0806 \\ e-mail) edm156@hotmail.com \\ and \\ KENNETH S. LYON \\ Professor, Ph.D \\ Department of Economics \\ Utah State University \\ Logan UT 84321 \\ Tel) 435-797-2292 \\ e-mail) klyon@econ.usu.edu
}

JEL Classification: Q 23

Key Words: Optimal Control Theory, Global Warming, Global Timber Market, Timber Supply Model, Ecological Change. 


\title{
A Dynamic Analysis of the Global Timber Market under Global Warming: An Integrated Modeling Approach
}

\begin{abstract}
We developed a dynamic integrated modeling approach to identify the effect of global warming on the global timber market. The Timber Supply Model 2000, BIOME 3, and Hamburg were used as a suitable economic and ecological model. The TSM 2000 was adopted to model dynamic economic behavior in the global timber market. BIOME 3 was utilized as our steady state ecological model, and Hamburg as our general circulation model. The TSM 200 was developed to consider more important up-to-date components in the global timber market. We estimated dynamic ecological change based on the simulation results of BIOME 3 using Hamburg and the linearlity assumptions about change in climate and ecosystem. With the estimates of dynamic ecological change, we modified the TSM 2000 to reflect the dynamic ecological change caused by climate change. After simulating the non-climate base scenario and the climate change scenario of the TSM 2000, we identified that global warming has a positive effect on the global timber market through an increase of timber productions causing stumpage prices to be lower than they otherwise would have been. In the welfare sense, we also examined that global warming is economically beneficial to society through the global timber market. For sensitivity analyses, we performed these simulation procedures under three different timber demand growth scenarios.
\end{abstract}




\section{INTRODUCTION}

Scientists and policy makers alike are concerned about global warming caused by the accumulation of carbon dioxide in the atmosphere. A significant number of studies have built comprehensive assessment models of carbon dioxide concentrations in the atmosphere over long time periods; however, most of these are deficient in the sense that they do not develop integrated assessment models that capture economic effects associated with global warming. In this vein, our research, as shown below, contributes to a growing body of literature that attempts to develop dynamic integrated models of ecosystem and economic system interactions that arise from predictions of global warming. We focus on the global timber market as a particular inquiry of global warming.

As global warming forces ecosystems to migrate toward the poles, the distribution of ecosystem types and the productivity of ecosystems will be altered. The transformation and adjustment of ecosystems resulting from climate change also change the environmental conditions under which natural resources, including forest products, are extracted and regenerated. It has been discussed and predicted that changes of forest types occur along two dynamic paths: dieback and regeneration (Shugart 1984, Solomon 1986, King and Neilson 1992). As climate change cause forest types to change along these dynamic paths, the global timber market will adjust as timber availability is altered.

In this context, we have developed an integrated modeling approach that identifies the effect of global warming on the global timber market. Most literatures that studied this objective have only investigated the effect of global warming on timber market in limited regions. Binkley (1988) studied the impact of global warming on boreal forests. Joyce et al. (1995), Burton et al. (1998), and Sohngen and Mendelsohn (1998) focused 